\title{
540 Development of a Multifunctional Fluid for Environmentally Friendly Machining
}

\author{
Satoshi SUDA ${ }^{1}$, Hideo YOKOTA ${ }^{2}$ and Toshiaki WAKABAYASHI ${ }^{3}$ \\ ${ }^{1}$ Nippon Oil Corporation, 8, Chidori-cho, Naka-ku, Yokohama 231-0815, JAPAN \\ E-mail: satoshi.suda@eneos.co.jp \\ ${ }^{2}$ Nippon Oil Corporation, 8, Chidori-cho, Naka-ku, Yokohama 231-0815, JAPAN \\ E-mail: hideo.yokota@eneos.co.jp \\ ${ }^{3}$ Kagawa University, 2217-20, Hayashi-cho, Takamatsu, Kagawa 761-0396, JAPAN \\ E-mail: twaka@eng.kagawa-u.ac.jp
}

\begin{abstract}
Summary
In manufacturing processes, the environmental issues concerning lubrication are not merely cutting fluids. Machine tools generally necessitate a variety of lubricants for its individual sliding and rotating parts, so that the application of environmentally acceptable lubricants to machine tools is of great significance. Further, since some of those lubricants are often contaminated with cutting fluids and disposed without adequate separation treatments, it must certainly be useful to develop a multifunctional fluid which is applicable to both machining and other lubricating parts.

In this study, therefore, a synthetic polyol ester is proposed as a base candidate of such multifunctional fluids. The candidate polyol ester can satisfy the cutting performance and secondary characteristics necessary for MQL lubricants. This ester is combined with a highly effective extreme pressure additive to prepare a potential lubricant as a multifunctional fluid. The developed fluid can demonstrate the excellent performance in MQL machining and the practically sufficient abilities for hydraulic and slideway lubrication.
\end{abstract}

Keywords: Environmental issues, MQL, Cutting fluids, Polyol ester, Biodegradability, Machine tools

\section{Introduction}

Programs that attempt to tackle environmental issues, such as the ozone layer destruction, the global warming effect and the environmental pollution, have been adopted throughout the world. In manufacturing processes, one logical step to avoid these problems is dry and near-dry machining where significant progress has recently been made. In particular, minimal quantity lubrication (MQL) machining has been accepted as a successful near-dry application because of its environmentally friendly characteristics, and a large number of studies have already presented that MQL machining can show the satisfactory performance in many practical machining operations ${ }^{(1)-(.3)}$.

A very small amount of a cutting lubricant plays an important role to accomplish the successful MQL machining ${ }^{(4)(5)}$. In this event, the potential MQL lubricants should have not only the high cutting performance, but also the preferable secondary characteristics, such as safety properties, biodegradability, oxidation stability and storage stability ${ }^{(6)}$.

The other way to solve the environmental issues concerning lubrication in the manufacturing processes may certainly be the application of environmentally acceptable lubricants to machine tools. A variety of lubricants are generally used for the machine tool parts, such as the slideway, spindle and hydraulic systems. Since some of them are often contaminated with cutting fluids and disposed without adequate separation treatments, it must certainly be useful to prepare one environmentally friendly lubricant applicable to both machining and other lubricating parts The purpose of this paper is therefore to develop a multifunctional fluid having the excellent MQL machining performance, sufficient abilities for machine tool lubrication and high biodegradability as an environmentally friendly lubricant.

\section{Experimental}

\subsection{Test lubricants and additives}

Table 1 shows the base stocks of lubricants used in this study. As a cutting lubricant of the MQL system, it should not have any unfavorable influence on environment. It may therefore be required to have high biodegradability, leading to some synthetic polyol esters and vegetable oils as a candidate ${ }^{(7)}$.
Table 1 Physical properties of base stocks

\begin{tabular}{|c|c|c|c|c|c|}
\hline & $\begin{array}{c}\text { Viscosity } \\
40^{\circ} \mathrm{C} \\
\mathrm{mm}_{2} / \mathrm{s}\end{array}$ & $\begin{array}{c}\text { Total Acid } \\
\text { Number } \\
\mathrm{mgKOH} / \mathrm{g}\end{array}$ & $\begin{array}{c}\text { Pour } \\
\text { Point } \\
{ }^{\circ} \mathrm{C}\end{array}$ & \multicolumn{2}{|c|}{$\begin{array}{c}\text { Biodegradability } \\
\text { CEC }\end{array}$} \\
\hline POE-A & 19.1 & 0.02 & $<-45$ & 100 & 72 \\
\hline POE-B & 31.9 & 0.60 & -20 & 100 & 69 \\
\hline VO-C & 36.3 & 0.31 & -20 & 100 & No \\
\hline VO-D & 35.6 & 0.92 & -20 & 100 & No \\
\hline
\end{tabular}


POE-A and POE-B are the biodegradable synthetic polyol esters with liner alkyl chains. They have recently been developed to provide the preferable performance in MQL machining ${ }^{(6)}$. VO-C is a highly refined vegetable oil and VO-D is an ordinary commercial vegetable oil. These vegetable oils have also been practically used as a conventional MQL lubricant.

In order to accomplish the required individual levels of the lubricating performance for a multifunctional fluid, the application of extreme pressure (EP) additives should probably be considered. Table 2 presents EP additives evaluated in this study. Based on preliminary screening friction tests, three additives, AD-1, -2 and -3 , have been chosen from the wide range of various organo-sulfur and organo-phosphorus compounds which are well-known as effective EP additives under the conditions of boundary lubrication. The details of their specific chemical structures are unavailable, unfortunately.

Table 3 shows the physical properties of commercially satisfactory hydraulic fluid HF-E and slideway oil SO-F. Each performance of them is the reference of the required lubricating level for the multifunctional fluid in each corresponding practical evaluation test described below.

\subsection{Performance evaluation of base stocks}

(a) Oxidation stability

When a MQL system is used, the lubricant may adhere onto the interior and exterior surfaces of the machine tools in the form of a thin oil film ${ }^{7}$. Since such a thin oil film can easily oxidize and form sticky substances, MQL lubricants should be stable against thin film oxidation. In order to simulate this thin film oxidation, $5 \mathrm{~g}$ of lubricant on an aluminum plate having a surface area of $200 \mathrm{~mm}^{2}$ were left in atmosphere at $70^{\circ} \mathrm{C}$ for $168 \mathrm{hrs}$. After this heating test, the change in the molecular weight was measured by gel permeation chromatography (GPC) analysis.

(b) Lubrication characteristics

The friction test apparatus is the modified Bowden-Leben type ball-on-plate friction tester, which is thought to be a fundamental and convenient method to understand the lubricity of base stocks themselves because the frictional conditions of this test are considered to be lie in the relatively moderate boundary lubrication region. Table 4 shows the conditions of this test and the coefficient of friction between the ball and the plate is obtained as a measure of the lubricity of test oils.

Table 4 Test conditions of ball-on- plate friction test

\begin{tabular}{|c|c|}
\hline Load & $1 \mathrm{~kg}$ \\
\hline Speed & $0.5 \mathrm{~mm} / \mathrm{seC}$ \\
\hline $\begin{array}{c}\text { Upper Specimens } \\
\text { Under Specimens }\end{array}$ & $\begin{array}{c}1 / 2 \mathrm{inch} \text { Steel Ball } \\
\text { JIS S30C Steel Plate }\end{array}$ \\
\hline Temperature & $25^{\circ} \mathrm{C}$ \\
\hline
\end{tabular}

\subsection{Performance evaluation of EP additives}

The situation of the boundary lubrication is considerably severe in hydraulic systems and slideways of machine tools, so that some effective EP additives are in general necessary to provide sufficient lubricity there. Under the circumstances, severer friction test should be applied in order to determine the acceptable performance of oils and a four-ball friction test may possibly be appropriate to the occasion rather than the above ball-on-plate friction tester. The method of the four-ball test is based on ASTM D2266. The test load is $396 \mathrm{~N}$, the rotation speed is $1800 \mathrm{rpm}$ and the test duration is 30 minutes. The wear scar diameter on the ball is measured to evaluate the lubricity of test oils.

2.4 Evaluation of practical performance

(a) Tapping test

The tapping test is well known as a standard screening method to evaluate the cutting performance $^{(8)(9)}$ and, in particular, the tapping energy efficiency is a sensitive and accurate evaluation basis ${ }^{(10)}$. The tapping energy efficiency is calculated by Eq. (1) and the conditions of this tapping test are shown in Table 5.

$$
\text { Tapping energy efficiency, } \%=\frac{\text { Tapping energy of reference oil }}{\text { Tapping energy of test sample }} \times 100
$$


(b) Wear test using rotary vane pump

Satisfactory lubrication given by hydraulic fluids plays a significant role to guarantee the smooth operation of pumps. The evaluation of the practical lubrication abilities of hydraulic fluids is often indicated by anti-wear characteristics described as $\mathrm{HM}$ grade requirements in ASTM D6158-99. Its testing method is specified in ASTM D2882 and its test conditions are shown in Table 6. The evaluation of anti-wear characteristics is carried out by the total wear amount of the vanes and the ring.

(c) Slideway test

There is no acceptable standard method to evaluate practically the lubricity of slideway oils. In this study, therefore, using the actual slideway of a turning machine, the coefficient of friction and the lost motion are measured to evaluate the slideway lubrication characteristics of test oils. Here, the value of the coefficient of friction is the average during sliding at a given constant feed speed. And the value of the lost motion is a distance of deviation between ordered and operated positions of the machine bed when it has moved as described in Japanese Industrial Standard (JIS) B6330 and at an operating speed of $1.2 \mathrm{~mm} / \mathrm{min}$. Table 7 shows the test conditions of this slideway test.

3.Results and discussion

3.1 Performance necessary for base stocks (a) Oxidation stability

Figure 1 shows the results of the oxidation stability test. The results are presented as increase rates of the molecular weight after the test compared with that before the test. If the molecular weight increases by more than $10 \%$, in general, one feels stickiness when touching. As a matter of fact, the oil films of VO-C and VO-D have become very sticky after the test. In contrast, POE-A and POE-B indicate no significant change in the molecular weight, demonstrating the preferable anti-oxidation characteristics as a MQL lubricant.

\section{(b) Lubrication characteristics}

Figure 2 shows the coefficient of friction obtained by the ball-on-plate friction tester. In this test, the polyol esters provide the somewhat lower coefficient of friction than that given by the vegetable oils. Further, the comparison between POE-A and POE-B suggests a fact that POE-B possesses the superior lubricating capability as a base stock to PO-A. This fact is probably connected with a difference of the total acid number between them.

As a result, from the standpoint of maintaining clean working environment and better lubricity, POE-B should be the optimal base stock for multifunctional fluids.
Table 6 Test conditions of wear test

\begin{tabular}{|c|c|}
\hline $\begin{array}{c}\text { Type of } \\
\text { Rotary Vane Pump. }\end{array}$ & Vickers 104C \\
\hline Test Method & ASTM D2882 \\
\hline Pump Speed & $1200 \mathrm{r} / \mathrm{min}$ \\
\hline Pump Outlet Pressure & $13.8 \mathrm{MPa}$ \\
\hline Fluid Temperature & $66^{\circ} \mathrm{C}$ \\
\hline Test Period & $100 \mathrm{~h}$ \\
\hline
\end{tabular}

Table 7 Test conditions of slideway test

\begin{tabular}{|c|c|}
\hline Slideway & Cast iron/Cast iron \\
\hline Feed Speed & $1.2,60,400 \mathrm{~mm} / \mathrm{min}$ \\
\hline & $15 \mathrm{~mm}(1.2 \mathrm{~mm} / \mathrm{min})$ \\
Feed Distance & $30 \mathrm{~mm}(40 \mathrm{~mm} / \mathrm{min})$ \\
& $300 \mathrm{~mm}(400 \mathrm{~mm} / \mathrm{min})$ \\
\hline Contact Pressure & $200 \mathrm{kPa}$ \\
\hline
\end{tabular}


3.2 Improvement of lubrication ability by EP additives

Figure 3 shows the wear scar diameter measured after the four-ball wear test. In this figure, the results obtained by commercial hydraulic fluid HF-E and slideway oil SO-F are also included for comparison. If POE-B contains no EP additive, its lubricity is inferior to those of the commercial lubricating oils. However, as expected, since EP additives chosen here can improve the anti-wear characteristics under the severe conditions of boundary lubrication, POE-B combined with each of these EP additives can provide the almost equivalent lubrication abilities to commercial ones. In particular, AD-3 is of great interest because it can work as an effective EP additive with an exceptionally small amount of dosage.

POE-B

$+A D-1(a \%)$

POE-B

$+A D-2(a * 1 / 5 \%)$

POE-B $A D-3(a * 1 / 100 \%)$

POE-B

HF-E

SO-F



Figure 3 Results of four-ball wear test ( $a \%=$ several\%) Since such a low content is normally eliminated from the estimation of environmental impact brought by a bulk substance, this finding may presumably be important in environmentally friendly formulation of lubricating oils.

From the above results, the combination of POE-B and AD-3 is expected to be one possible answer to the multifunctional fluid and its practical performance should individually be examined. This combination is hereafter designated as 'MF' for convenience' sake.

3.3 Evaluation of individual practical performance

(a) Cutting performance

Figure 4 shows the results of the tapping test in the case of MQL cutting with several lubricants, that is MF, POE-A, POE-B and VO-D. For comparison, this figure also shows the results in the case of conventional flood supply of a water-soluble coolant (JIS K224l type A1). Since the performance of MQL cutting with $\mathrm{MF}$ is almost equal to that of conventional cutting, a very small amount of this lubricant is found to be highly effective This is particularly true in machining of JIS S25C steel and thus MF is determined as a preferable lubricant for MQL machining .

(b) Anti-wear performance as a hydraulic fluid

Figure 5 shows the results of the total wear amount of the vanes and the ring in the rotary vane pump. Its accepted level by ASTE is less than $50 \mathrm{mg}$ and, of course as seen here, HF-E which is widely used as a commercial hydraulic fluid indicates the satisfactory anti-wear performance. Then MF can further reduce the wear amount, quite smaller than that of HF-E, meaning the EP additive included in MF has the excellent anti-wear ability in practical use.

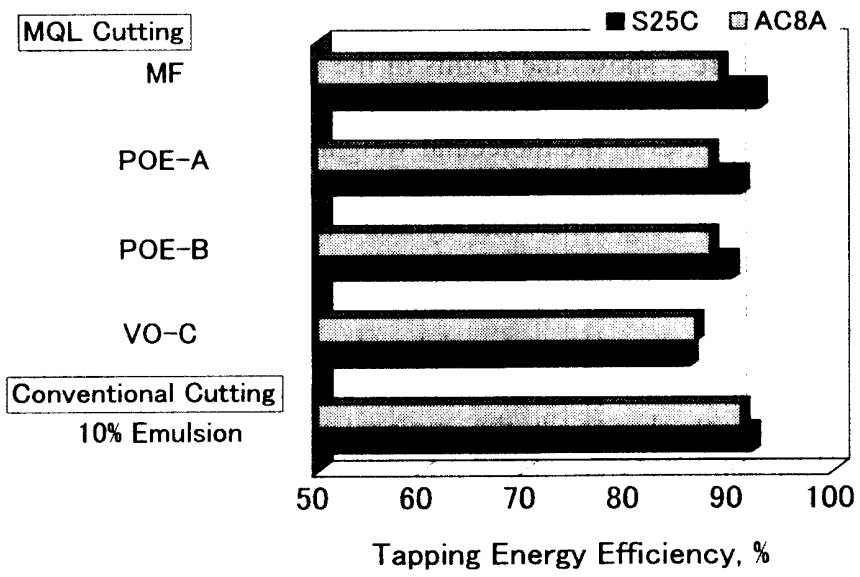

Figure 4 Results of tapping test

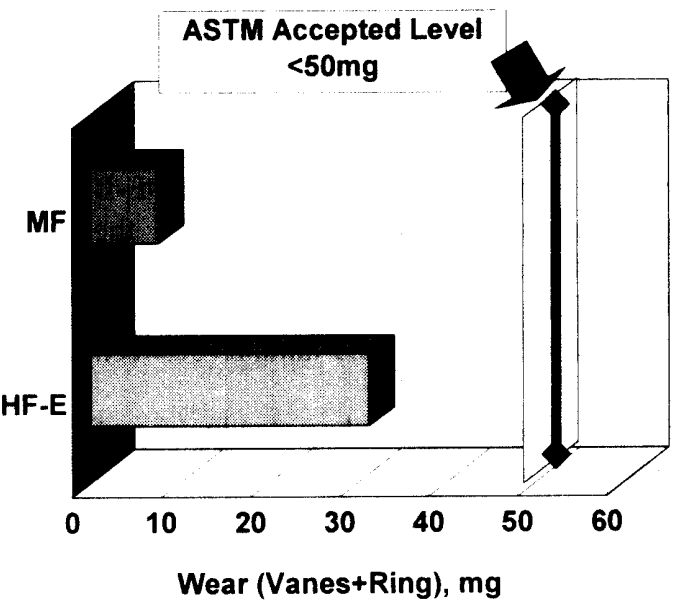

Figure 5 Results of rotary vane pump Test (ASTMD2882) 
(c) Friction and motion characteristics on slideway

Figures 6 (a) and (b) show the results of the slideway test: the coefficient of friction and the lost motion, respectively. These results suggest that MF has the preferable performance compared with commercial slideway oil SO-F in this actual slideway test. In addition, it should be noted that, although the viscosity of $\mathrm{MF}$ is in the range of VG32, MF can provide the better friction and motion characteristics than SO-F whose viscosity is in the range of VG68, probably because EP additive AD-3 may work effectively.

(a) Coefficient of friction

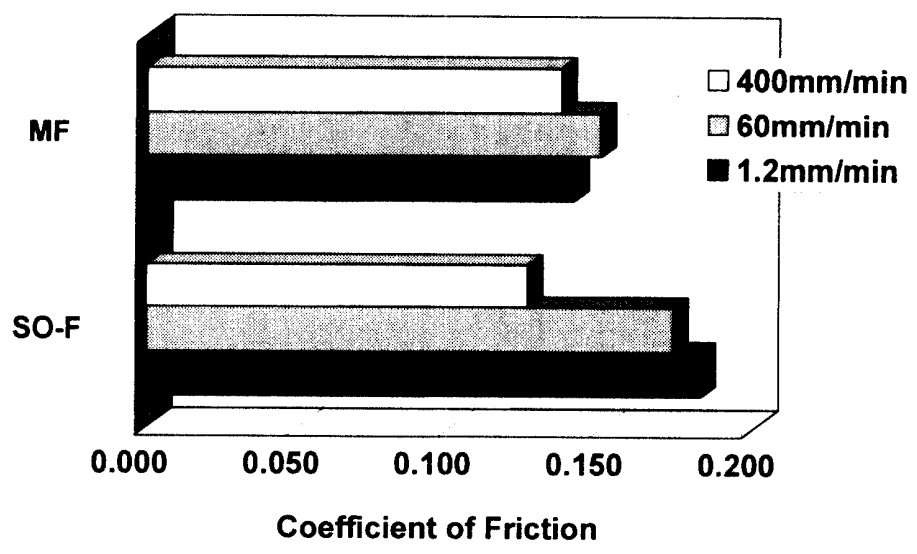

(b) Lost motion

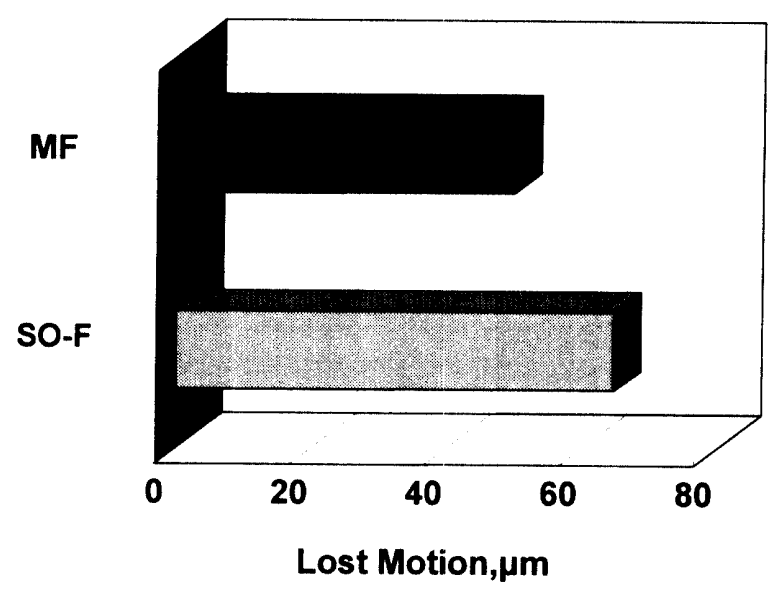

Figure 6 Results of slideway test

4. Conclusions

In order to develop a multifunctional fluid, a biodegradable synthetic polyol ester is chosen as a candidate of base stocks and this polyol ester is combined with a organo-phosphorus compound which is a highly effective extreme pressure additive with an exceptionally small amount of dosage. The developed multifunctional fluid can demonstrate the excellent performance in MQL machining and the practically sufficient abilities for hydraulic and slideway lubrication. As a result, this multifunctional fluid is expected to be a potential lubricant applicable to both machining and other lubricating parts in practical use.

5. References

(1) F. Klocke, et al., 1999, Coated Tools for Metal Cutting-Features and Applications, Annals of the CIRP, 48/2 pp515-525

(2) F. Klocke, 1997, Dry Cuttig, Annals of the CIRP, 46/2 pp519-526

(3) S. Suda., et al., 2001, Evaluation of Machinability with MQL System and Effectiveness in Production Lines, Proceedings of the International Tribology Conference Nagasaki, 2000, pp203-208

(4) J. W. Sutherland, et al., 2000, An Experimental Investigation of Air Quality in Wet and Dry Turning, 
Annals of the CIRP, 49/1 pp61-64

(5) U. Heisel, et al., 1994, Application of Minimum Quantity Cooling Lubrication Technology in Cutting Processes, Production Engineering, Vol.II/1. pp49-54

(6) S. Suda, et al., A Synthetic Ester as an Optimal Cutting Fluid for Minimal Quantity Lubrication Machining, Annals of the CIRP, $51 / 1$ pp $95-98$

(7) 1996. Biodegradable Fluids and lubricants. Ind. Lub \& Trib., 48/2. 17-26

(8) E. N. Ladov, 1974, A Tapping Test for Evaluating Cutting Fluids,Lubr.Eng, 30/1, pp5-9

(9) W. A. Faville, et al, 1978, The Falex Tapping Torque Test Mechine, Lubr.Eng, 34/4, pp193-197

(10) T. Wakabayashi., 1990, Evaluation of Cutting Fluids by Consumption Energy in Tapping Test , Lubr. Eng., $46 / 11$ pp $715-720$ 